\title{
Simulation Center Partnership:A University and Community Hospital Collaboration for Healthcare Education
}

\author{
Jennifer DellAntonio*1, Darlene Ardary ${ }^{1}$, Joy DuGan ${ }^{1}$, Stephanie McKee ${ }^{1}$, Bridget Conklin ${ }^{1}$, Darlene Hepler ${ }^{1}$ and \\ Dolores Hanna ${ }^{1}$
}

${ }^{1}$ Department of Nursing, Lock Haven University, Clearfield, USA

Submission: September 13, 2018 Published: September 21, 2018

*Corresponding author: Jennifer DellAntonio, Associate Professor, Chair, Department of Nursing, Lock Haven University, Clearfield, USA, Tel: 814-768-3426; Email: JKD1313@lockhaven.edu

\begin{abstract}
This article introduces a rural university and community hospital collaboration.Lock Haven University Nursing Department located in rural Pennsylvania, devised a solution that is not only beneficial to the university, but to students and a local clinical facility. The development of a hospital-based simulation center partnership designed to create a dynamic comprehensive high-fidelity simulation with practical applications for pre-licensure nursing students and community health care workers.The collaboration will allow students to learn in an environment that is set in a retired Intensive Care Unit. Unique to the LHU Nursing and Penn Highlands collaboration, is utilizing a simulation that applies real patient information coupled with supportive case scenarios. The Simulation Center provides a positive learning experience in which students refine their patient management skills and collaborate with multidisciplinary team members.
\end{abstract}

Keywords: Simulation; Nursing; Interprofessional Collaboration

\section{Introduction}

The Lock Haven University, Associate of Science in Nursing program (ASN) and Penn Highlands Clearfield, a local hospital in rural Pennsylvania have joined together in a partnership to provide simulation education. Utilizing joined resources, we have found this to be cost effective and to provide students and healthcare workers with optimal learning opportunities. This venture began after numerous failed attempts to raise money for a new and comprehensive simulation center at the university. Wanting the best for our students, our simulation program led to brainstorming. The cost to build and sustain a high-fidelity simulation environment is immense. Our faculty recognized that during the current economic climate and hardships, it may also be difficult for clinical facilities to offer such valuable learning opportunities. Thus, we devised a plan for the possibility of shared resources with a local hospital. With recent restructuring, the hospital closed their intensive care unit, an area that was currently not being utilized. This area included everything that we had included in our previous plans for a new simulation center and more. In support of our university mission statement, a simulation center in this area and with the possibility of interprofessional collaboration, would provide our nursing students with a most realistic, real-world environment for learning.After over a year of discussions with the hospital, university representatives, and legal teams, a collaborative agreement for a Simulation Center was signed. The 8-bed center opened in September of 2017 and houses simulators from the university nursing program and the hospital for education of nursing students, hospital healthcare workers, and community-based education. This center is equipped with patient care rooms, a nurse's station, supply room and a conference room for debriefing. The unit is housed with everything that you would see on a 'real' patient care unit, such as computers, hand sanitizers, IV pumps, a crash cart, and defibrillator.In addition, the Simulation Center is equipped with the essential video equipment needed in simulation setups. For example, the advanced video technology, such as a wearable action camera can deliver a revealing perspective fromthe student or simulator point of view.This innovative video technology can be mounted on a student or simulator to capture the field of view of a participant. The innovative use of this action camera in the ASN program enabled students touse this technology to enhance and practice communication and awareness.In addition, the Simulation Lab Coordinator, employed by both the hospital and the university, organizes the center and funding for simulation maintenance is to be shared by both parties. By sharing resources and cost, the Simulation Center sustainability is more financially stable and the possibilities for use increased. 


\section{Evidence Supporting Use of Simulation in Nursing Education}

There is a plethora of research conducted within the realm of simulation. We share only highlights of the foundation in simulation research that supported our initiative. Research shows simulation in nursing education can be an effective method for teaching and learning. Although simulation has been used in nursing education for over the past 20 years, it has gained increased interest and acceptance with the Institute of Medicine (1999) movement for increased quality and safety with patient care. Embracing evidence-based practices was an important step in the creation and success of the Simulation Center. The shift towards the use of simulation for nursing education and education of healthcare employees has progressively increased in response to this need. Recently, after a large, national study $(n=666)$, conducted by the National Council of State Board of Nursing (NCSBN) found no significant difference in the clinical competency and knowledge of students who used simulation for clinical education for 10, 25 , or 50 percent of their clinical education [1]. The National League for Nursing (NLN) endorsed this study and the findings (2015).Furthermore, they promote simulation as an effective and evidence-based method for fostering critical thinking and reasoning skills for patient care [2]. In addition to those benefits of simulation, this methodology has been found to facilitate teamwork and mastery of practical skills related to clinical care [3-5]as well as cognitive skills [6,7].Simulation based learning has been found to be an effective tool to improve early recognition of clinical decline [8] and build confidence and knowledge in critical care situations[9].For example, students are paired together as a teaching strategy to foster team communication and collaboration. Participant preparation is necessary for students to successfully accomplish simulation objectives [10].Unlike a classroom setting or a paper and pencil test, simulation allows the learner to function in an environment that is as close as possible to an actual clinical situation and provides them the opportunity to "think on their feet, not in their seat" [11]. This allows the student to hone their clinical skills without danger of harming the patient during the learning process [12].Simulations can also immerse the trainee in a safe practice environment that may be too dangerous in the real world or expose them to situations that occur infrequently [12].The use of simulation in education is not just for nursing students.Other healthcare professionals implementing the use of simulation will "enable the learner to practice necessary skill in an environment that allows for errors and professional growth without risking patient safety" [13]. As the need to produce quality nursing students and other health care professionals grows, the need for clinical space in the hospital setting becoming harder to obtain. The use of this hospital-based simulation center will allow the professional nursing student to experience real life scenarios that they might not see until well after graduation. Being able to work on critical thinking skills in the didactic and clinical arena will allow nurse educators to safely prepare our students for practice. Students will learn how to resolve or understand what is going on with their patients in a safe and effective learning arena. This vital to the success of our students.

\section{Unique Simulation Experience Opportunity}

With the opening of the new Simulation Center located in our local community hospital, the Lock Haven University nursing faculty were interested in developing meaningful but unique simulation encounters for nursing students with emphasis on beginning practice competencies, including communication skills when collaborating with physicians and other health care professionals.To create a real-world experience, the simulation center within the hospital setting was the perfect opportunity to incorporate a unique learning experience combining both simulation and traditional clinical experience. Being mindful of our course outcomes, targeted concepts for learning included safety, communication, collaboration with the health care team, team work, prioritizing and decision making. This unique experience includes a real patient connection to the simulation scenarios[14-16].The scenarios developed are based on the real patients admitted to the clinical medical surgical floor below. Students can meet the actual patients prior to their simulation experience. The students come to the clinical unit the day before their clinical simulation experience with their traditional clinical experience peers. The students assigned to the clinical experience students are required to do the same clinical preparation as their traditional clinical peers. Patient selection and simulation case development is population based and reflects the high frequency admission diagnoses of Congestive Heart Failure, Diabetes, and Chronic Obstructive Pulmonary Disease.The students participating in the simulation center are pre-licensure associate degree nursing students learning the Quality and Safety Education for Nurses (QSEN) competencies, patient safety, assessment, communication, teamwork and collaboration.Developing nursing judgment, competence in essential skills, and confidence in their ability to communicate, recognize patient decline and intervene appropriately are the primary objectives providing structure for the Simulation Center's activities. LHU Nursing faculty asked students who attended the new Simulation Center to complete a survey asking about their experience. The results were positive. Ninety-six percent of the students completing the survey $(n=50)$ either agreed or strongly agreed to the following questions:

a) Simulating medical emergencies is an effective teaching tool.

b) Helped me recognize the signs and symptoms of patient decline or improvement;

c) Improve team communication skills and evaluate my patient's environment for safety.

\section{Community Collaboration Priorities and Utilization}

Priorities of this collaboration place focus on providing high quality clinical care instruction for improved preparation of clinicians to provide optimal care and reduce client complications 
and recovery time. The clinicians include our nursing students and hospital personnel. Both the hospital and the university provide highly qualified and competent instructors to guide the learning experience utilizing realistic scenario development and debriefing for student/healthcare provider self-identification of learning needs.Short-term outcomes include active participation by users in the assessment, planning, intervention, and analysis of care utilizing the application of theory in a risk-free environment. Intermediate outcomes allude to an increased skill and knowledge base, increased self-confidence and critical thinking abilities, and an increased ability to work as a team member. Ultimately, the use of the Simulation Center will impact the provision of highly skilled and competent novice nurses and clinicians entering the clinical care workforce, increased knowledge of current healthcare providers related to high risk and safety issues and less client complications, mortality and shorter hospital stays. One of the future goals for the use of the Simulation Center is to increase community collaboration by developing and implementing a disaster preparedness training simulation. In addition, we will address the use of the Simulation Center as the center for LHU's interprofessional educational initiative (IPE) to promote team based, patient-centered care. Simulation in this hospital-based simulation center helps not only LHU nursing students to meet their learning goals, but also the goals of the health care facility, such as patient safety and best practices.For example, Penn Highlands Clearfield's Education Department uses the Simulation Center for influenza nasal swabbing procedure instruction, Advanced Cardiac Life Support (ACLS) training, obstetric emergencies for the Emergency Department staff and Safe Haven Response Team protocol. Initiatives continue to embrace opportunities within the community and other health care educational institutions. For example, faculty within the university developed an interprofessional collaboration with students in athletic training, physician assistant, nursing and social work departments. The scenario was based on a head injured athlete on the athletic field and transported to the 'Emergency Room' simulation center. This half day scenario played out with both university and hospital clinicians involved which included a debriefing and video review[17].

\section{Conclusion}

Lock Haven University (LHU) along with Penn Highlands have collaborated to develop and utilize a retired ICU unit as a Simulation Center. This university partnership with a healthcare facility can maximize educational impact, as well as provide shared funding and resources. Our simulation center partnership and how it works well for the education of current and future healthcare workers is the foundation to its success and sustainability. The simulation center within the hospital setting incorporates a unique learning experience combining both simulation and traditional clinical experience to create a realword experience for our nursing students.

\section{References}

1. Hayden JK, Smiley RA, Alexander M, Kardong-Edgren S, Jeffries PR (2014). Supplement: The NCSBN National Simulation Study: A longitudinal, randomized, controlled study replacing clinical hours with simulation in prelicensure nursing education. Journal of Nursing Regulation, 5(2), C1-S64.

2. National League for Nursing (2015,April 20). A vision for teaching with simulation.

3. Sebold LF, Boell JE, Girondi JB, Santos JL (2017). Clinical simulation: Development of relational competence and practical skills in nursing fundamentals. Journal of Nursing 11(10): 4184-4190.

4. MacLean S, Kelly M, Geddes F, Della P (2017). Use of simulated patients to develop communication skills in nursing education: An integrative review. Nurse Education Today 48: 90-98.

5. Simko LC, Henry R, McGinnis KA, Kolesar AL (2014). Simulation and mock code: A safe way for nursing students to learn. Journal of Nursing Education \& Practice4(7): 95-103.

6. Aebersold M, Tschannen D(2013). Simulation in nursing practice: The impact on patient and confidence levels. The Online Journal of Issues in Nursing 18(2): 6.

7. Beddingfield S, Davis BW, Gilmore Mm, Jenkins L (2011). The effect of high-fidelity simulation on examination performance. Teaching \& Learning in Nursing 6(2): 46-49.

8. Bell-Gordan C, Gigliotti E, Mitchell K (2014)An evidence-based practice project for early recognition of clinical deterioration: utilization of simulation-based education. J Nurs Educ Practice4(6): 69-76.

9. Boiling B, Hardin Pierce M (2016). The effects of high-fidelity simulation on knowledge and confidence in critical training an interactive review. J Nurs Educ Practice 16(1): 287-293.

10. Meakim C, Fey M, Chmil J, Mariani B, Alinier G, et al. (2015). Standards of best practice: Simulation Standard IX: Simulation Design. Clinical Simulation in Nursing 11(6): 309-315.

11. Shin S, Park J, Kim J (2015). Effectiveness of patient simulation in nursing education: meta-analysis. Nurse Education Today 35(1): 176182.

12. Orique SB, Phillips LJ (2018). The effectiveness of simulation on recognizing and managing clinical deterioration: Meta-analyses. Western Journal of Nursing Research 40(4): 582-609.

13. Benner P, Sutphen M, LeonardV,Day L (2010). Educating Nurses: A Call for Radical Transformation. Jossey-Bass,San Francisco California, USA

14. (2016) INACSL Standards Committee. INACSL Standards of best practice: Simulation design. Clinical Simulation in Nursing 12(s): 5-12.

15. Institute of Medicine (IOM). (1999). To err is human: Building a safer health system(L. T. Kohn, J. M. Corrigan, \& M. S. Donaldson, Eds.). Washington, DC: National Academy

16. Interprofessional Education Collaborative Expert Panel. (2011). Core competencies for interprofessional collaborative practice: Report of an expert panel.Washington, D.C.: Interprofessional Education Collaborative.

17. Quality and Safety Education for Nurses (2012). Teaching strategies. 

(C) This work is licensed under Creative

DOI: 10.19080/JOJNHC.2018.09.555769
Your next submission with Juniper Publishers will reach you the below assets

- Quality Editorial service

- Swift Peer Review

- Reprints availability

- E-prints Service

- Manuscript Podcast for convenient understanding

- Global attainment for your research

- Manuscript accessibility in different formats

( Pdf, E-pub, Full Text, Audio)

- Unceasing customer service

Track the below URL for one-step submission https://juniperpublishers.com/online-submission.php 